FOLIA POMERANAE UNIVERSITATIS TECHNOLOGIAE STETINENSIS

Folia Pomer. Univ. Technol. Stetin., Oeconomica 2017, 337(88)3, 47-56

Joanna PERZYŃSKA

\title{
PROGNOZY KOMBINOWANE W TESTOWANIU OBEJMOWANIA MODELI EKONOMETRYCZNYCH - PRZYKŁAD EMPIRYCZNY
}

\author{
COMBINED FORECASTS IN TESTING OF ECONOMETRIC MODELS \\ ENCOMPASSING - EMPIRICAL EXAMPLE
}

Katedra Zastosowań Matematyki w Ekonomii, Zachodniopomorski Uniwersytet Technologiczny w Szczecinie, ul. Klemensa Janickiego 31, 71-270 Szczecin, e-mail: joanna.perzynska@zut.edu.pl

\begin{abstract}
Summary. In the paper, the author considers the situation in which several econometric models of the same variable are available. Then the main problem is to select the best model. For this purpose they are generally used measures of model fit to the empirical data. An alternative approach is testing of encompassing. In the paper, the author presents theoretical considerations about forecast encompassing. In this case we can use combined forecasts being weighted average of individual forecasts determined on the basis of competing models The illustration of theoretical considerations is the empirical example, in which the costs of heat and electricity production in a power plant $\mathrm{B}$ are modeling and forecasting.
\end{abstract}

Słowa kluczowe: model ekonometryczny, obejmowanie modeli względem prognoz, prognozy kombinowane, testowanie obejmowania modeli.

Key words: combined forecasts, econometric model, forecast encompassing, testing of encompassing.

\section{WSTĘP}

Model ekonometryczny, opisujący zależności w sferze zjawisk ekonomicznych, jest uproszczonym odwzorowaniem rzeczywistości - uwzględnia tylko główne czynniki określające zmienność danego zjawiska (Wprowadzenie do ekonometrii... 2004; Welfe i Welfe 2004). Budowa modelu ekonometrycznego przebiega w kilku etapach. W zależności od decyzji podjętych na każdym z nich (wyboru: zmiennych objaśniających, klasy modelu, jego postaci analitycznej czy metody estymacji parametrów) po etapie weryfikacji można otrzymać zbiór wielu rywalizujących ze sobą modeli, które mają zbliżone właściwości. W takiej sytuacji alternatywnym podejściem w poszukiwaniu najlepszego modelu na podstawie oceny miar dobroci dopasowania do danych empirycznych może być testowanie obejmowania modeli.

Dany model obejmuje model rywalizujący, jeżeli może objaśniać zachowanie jego cech (Mizon i Richard 1986). Cechami uwzględnianymi w obejmowaniu może być wariancja reszt modelu (variance encompassing) lub błędy prognoz (forecast encompassing). Niniejszy artykuł dotyczy obejmowania względem prognoz, do testowania którego wykorzystuje się prognozy kombinowane będące średnią ważoną prognoz indywidualnych wyznaczonych na podstawie rywalizujących modeli. 
llustracją rozważań teoretycznych jest przykład empiryczny, w którym modelowaniu i prognozowaniu poddano zmienną ekonomiczną w postaci szeregu czasowego z wahaniami sezonowymi. Procedura badawcza przebiegała w kilku etapach. W pierwszym etapie oszacowano po kilkanaście modeli należących do różnych klas. Ponieważ na podstawie oszacowanych modeli miały być wyznaczone prognozy, w pierwszym etapie, poza badaniem dopasowania modeli do danych empirycznych, badano też ich własności predyktywne. Dopiero wybrane w ten sposób modele po ponownym oszacowaniu wykorzystano do testowania obejmowania względem prognoz. W tym celu na podstawie reestymowanych modeli wyznaczono prognozy indywidualne, a następnie oszacowano odpowiednie równania regresji przedstawiające prognozy kombinowane oraz zbadano statystyczną istotność ich parametrów strukturalnych. W toku badań zweryfikowano hipotezę mówiącą, że testowanie obejmowania modeli względem prognoz jest użyteczną metodą wyboru najlepszych modeli ze zbioru modeli rywalizujących.

\section{METODY}

Model $\mathrm{M}_{1}$ obejmuje model $\mathrm{M}_{2}$ względem prognoz (forecast encompassing), jeżeli może objaśnić błąd prognoz wyznaczonych na podstawie modelu $M_{2}$ (por. Mizon i Richard 1986; Clements i Hendry 1993; Charemza i Deadman 1997). Do testowania obejmowania modeli względem prognoz wykorzystuje się metodologię łączenia prognoz indywidualnych w prognozę kombinowaną. Idea wyznaczania prognoz kombinowanych, będących średnimi ważonymi par prognoz nieobciążonych, została przedstawiona przez Batesa i Grangera (1969), jednak rok wcześniej Pawłowski (1968) zaproponował połączenie dostępnych prognoz i wyznaczenie ich średniej arytmetycznej prostej lub ważonej.

Niech $f_{1 t}$ i $f_{2 t}$ będą dwiema różnymi prognozami wartości tej samej zmiennej $Y$ na okres $t\left(y_{t}\right)$, otrzymanymi na podstawie dwóch rywalizujących modeli - odpowiednio $M_{1}$ oraz $M_{2}$. Obie prognozy indywidualne można połączyć w prognozę kombinowaną o postaci:

$$
f_{c t}=(1-\lambda) f_{1 t}+\lambda f_{2 t}
$$

gdzie:

$\lambda$ - waga prognozy $f_{2 t}(0 \leq \lambda \leq 1)$.

Jeżeli prognoza wyznaczona na podstawie modelu $M_{2}$ nie zawiera żadnych przydatnych informacji, które są nieobecne $w$ prognozie wyznaczonej na podstawie modelu $M_{1}$, to w prognozie kombinowanej (1) $\lambda=0, f_{c t}=f_{1 t}$. W takiej sytuacji preferowana jest prognoza $f_{1 t}$, którą Granger i Newbold (1973) określili jako warunkowo efektywną w odniesieniu do rywalizującej prognozy $f_{2 t}$. W przedstawionym przypadku model $M_{1}$ obejmuje model $M_{2}$ względem prognoz, co skrótowo nazywa się obejmowaniem prognozy $f_{2 t}$ przez prognozę $f_{1 t}$ (Chong i Hendry 1986; Clements i Hendry 1993).

Badanie obejmowania prognoz z wykorzystaniem prognozy kombinowanej polega na testowaniu statystycznej istotności parametru (wagi) $\lambda \mathrm{w}$ odpowiadającym prognozie (1) równaniu regresji (Granger i Newbold 1973):

$$
e_{1 t}=\lambda\left(e_{1 t}-e_{2 t}\right)+e_{c t}
$$

gdzie:

$$
e_{i t}=y_{t}-f_{i t}
$$


$e_{c t}=y_{t}-f_{c t}$

$e_{i t}, e_{c t}$ - błędy prognoz indywidualnych $f_{i t}(i=1,2)$ oraz prognozy kombinowanej.

Zerowa hipoteza obejmowania prognozy $f_{2 t}$ przez prognozę $f_{1 t}$ ma wówczas postać:

$H_{0}: \lambda=0$

Naturalnym testem zerowej hipotezy w regresji (2) szacowanej KMNK jest test t-Studenta.

Obejmowanie w przypadku prognozy kombinowanej, będącej średnią ważoną większej liczby prognoz indywidualnych, przedstawili Harvey i Newbold (2000). Przy założeniu sumowania się nieujemnych wag do jedności prognoza kombinowana ma postać:

$$
f_{c t}=\sum_{i=1}^{m} \lambda_{i} f_{i t}
$$

gdzie:

$i=1,2, \ldots, m(m \geq 2)$,

$m$ - liczba prognoz składowych prognozy kombinowanej,

$f_{i t}-i$-ta prognoza indywidualna na okres $t$, wyznaczona na podstawie modelu $M_{i}$,

$\lambda_{i}$ - waga prognozy $f_{i t}\left(0 \leq \lambda_{i} \leq 1\right)$.

Powyższej prognozie odpowiada równanie regresji:

$$
e_{1 t}=\sum_{i=2}^{m} \lambda_{i T}\left(e_{1 t}-e_{i t}\right)+e_{c t}
$$

Zerową hipotezę obejmowania prognoz indywidualnych $f_{2 t}, f_{2 t}, \ldots, f_{m, t}$ przez prognozę $f_{1 t}$ można zapisać w postaci:

$$
H_{0}: \lambda_{2}=\lambda_{3}=\ldots=\lambda_{m}=0
$$

Naturalnym testem zerowej hipotezy (8) w regresji (7) jest test $F$.

Testowanie obejmowania modeli daje możliwość bezpośredniego porównania modeli indywidualnych, udzielając tym samym odpowiedzi na pytanie, czy należy odrzucić dany model na rzecz modelu rywalizującego (Charemza i Deadman 1997).

\section{PREZENTACJA I OCENA WYNIKÓW}

W przykładzie empirycznym wykorzystano dane przedstawiające koszty produkcji energii cieplnej i elektrycznej (KCE) w elektrowni B. Szereg czasowy wartości zmiennej KCE (w tys. zł) obejmował okres 60 miesięcy; jego kształtowanie przedstawiono na ryc. 1.

W pierwszym etapie, na podstawie danych pochodzących z okresu estymacyjnego obejmującego 36 obserwacji, oszacowano modele ekonometryczne należące do pięciu klas:

- klasyczne modele szeregu czasowego ze stałą i zmienną sezonowością,

- hierarchiczne modele szeregu czasowego ze stałą i zmienną sezonowością (por. Zastosowanie hierarchicznych modeli... 2003),

- klasyczne modele przyczynowo-opisowe ze zmieniającymi się sezonowo parametrami,

- hierarchiczne modele przyczynowo-opisowe ze zmieniającymi się sezonowo parametrami,

- adaptacyjne modele Holta-Wintersa. 


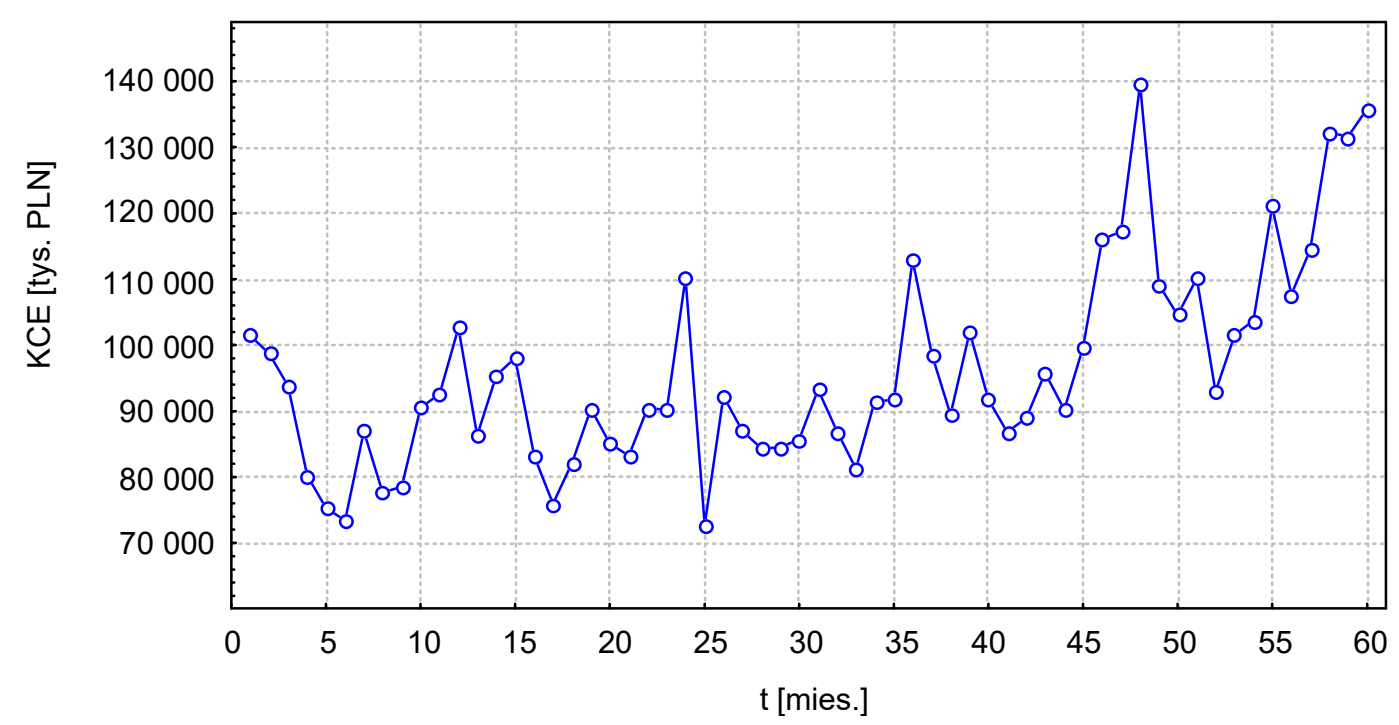

Ryc.1. Kształtowanie zmiennej KCE

Dla każdej klasy dokonano estymacji kilkunastu modeli różniących się: analityczną postacią funkcji trendu, rodzajem wahań sezonowych, zmiennymi objaśniającymi, stałymi wygładzania. Dodatkowo, w celach porównawczych, zbudowano też modele sztucznych sieci neuronowych (perceptrony wielowarstwowe) o różnej strukturze (liczbie warstw ukrytych oraz ich neuronów) - por. Perzyńska (2010).

$\mathrm{Na}$ podstawie wszystkich oszacowanych modeli wyznaczono prognozy ex-post dla horyzontu dwunastomiesięcznego i dokonano oceny ich trafności. Następnie z każdej z klas wybrano po jednym modelu charakteryzującym się najlepszymi właściwościami (wysokim dopasowaniem do danych empirycznych, istotnymi parametrami strukturalnymi oraz najmniejszymi błędami prognoz): $M_{1}, M_{2}, \ldots, M_{6}$ ( $M_{1}$ - klasyczny model szeregu czasowego, $\mathrm{M}_{2}$ - hierarchiczny model szeregu czasowego, $\mathrm{M}_{3}$ - klasyczny model przyczynowo-opisowy, $\mathrm{M}_{4}$ - hierarchiczny model przyczynowo-opisowy, $\mathrm{M}_{5}$ - adaptacyjny model Holta-Wintersa, $\mathrm{M}_{6}$ - sztuczna sieć neuronowa).

W drugim etapie dokonano reestymacji parametrów klasycznych i hierarchicznych modeli $\mathrm{M}_{1}-\mathrm{M}_{4}$ dla okresu estymacyjnego obejmującego 48 obserwacji. W tabeli 1 zestawiono oceny miar dobroci dopasowania oraz parametrów struktury stochastycznej oszacowanych modeli.

Tabela 1. Oceny miar dobroci dopasowania oraz parametrów struktury stochastycznej klasycznych i hierarchicznych modeli szeregu czasowego oraz modeli przyczynowo-opisowych

\begin{tabular}{|l|r|r|r|r|}
\hline \multicolumn{1}{|c|}{ Parametr } & $\mathrm{M}_{1}$ & $\mathrm{M}_{2}$ & $\mathrm{M}_{3}$ & $\mathrm{M}_{4}$ \\
\hline$R^{2}[\%]$ & 82,80 & 72,00 & 85,43 & 77,96 \\
\hline $\mathrm{Se}$ & 7214,27 & 7516,6 & 4745,63 & 5835,82 \\
\hline Ve $[\%]$ & 7,87 & 8,20 & 5,17 & 6,36 \\
\hline
\end{tabular}

We wszystkich klasycznych i hierarchicznych modelach oceny wyrazów wolnych, współczynników kierunkowych funkcji trendu oraz dodatkowo parametrów przy jednej zmiennej objaśniającej w modelach przyczynowych są statystycznie istotne. Ponadto modele te posiadają istotne składniki sezonowe. $Z$ informacji zawartych $w$ tab. 1 wynika, że 
oszacowane modele charakteryzują się stosunkowo wysokim dopasowaniem do danych empirycznych - wartość współczynnika determinacji wynosi od 72,00\% (hierarchiczny model szeregu czasowego $\mathrm{M}_{2}$ ) do 85,43\% (klasyczny model przyczynowo-opisowy $\mathrm{M}_{3}$ ). Współczynniki zmienności losowej reszt przyjmują wartości od $5,17 \%$ do $8,20 \%$ - najmniejszą wartość otrzymano dla klasycznego modelu przyczynowo-opisowego, zaś największą dla hierarchicznego modelu szeregu czasowego.

Podczas szacowania modelu adaptacyjnego oraz sztucznej sieci neuronowej nie są wyznaczane klasyczne miary dobroci dopasowania, lecz jedynie mierniki bezwzględne błędy pomiędzy wartościami empirycznymi a teoretycznymi (odpowiednio wartościami wyrównanymi lub wyjściowymi). Z tego względu bezpośredniego porównania wszystkich modeli dokonano na podstawie analizy trafności prognoz indywidualnych, które posłużyły do budowy prognoz kombinowanych. Na podstawie wszystkich sześciu modeli wyznaczono indywidualne prognozy ex-post dla horyzontu dwunastomiesięcznego ( $t=49,50, \ldots, 60$ ), oznaczając je odpowiednio: $f_{1}, f_{2}, \ldots, f_{6}$. Średnie absolutne błędy procentowe wyznaczonych prognoz MAPE (Mean Absolute Percentage Error) zestawiono w tab. 2.

Tabela 2. Oceny średnich absolutnych błędów procentowych MAPE prognoz indywidualnych

\begin{tabular}{|c|c|}
\hline Prognoza & MAPE [\%] \\
\hline $\mathrm{f}_{1}$ & 11,80 \\
\hline $\mathrm{f}_{2}$ & 11,80 \\
\hline $\mathrm{f}_{3}$ & 10,15 \\
\hline $\mathrm{f}_{4}$ & 10,50 \\
\hline $\mathrm{f}_{5}$ & 9,84 \\
\hline $\mathrm{f}_{6}$ & 8,26 \\
\hline
\end{tabular}

Analizując informacje zawarte $w$ tab. 2, można zauważyć, że najniższe oceny błędów MAPE otrzymano dla prognoz wyznaczonych na podstawie modelu $M_{6}$ (sztucznej sieci neuronowej) i modelu $\mathrm{M}_{5}$ (Holta-Wintersa). Największe błędy, wynoszące $11,8 \%$, otrzymano dla prognoz wyznaczonych na podstawie klasycznych i hierarchicznych modeli szeregu czasowego $\left(\mathrm{M}_{1}\right.$ i $\left.\mathrm{M}_{2}\right)$. Należy zwrócić uwagę, że model $\mathrm{M}_{2}$ (w przeciwieństwie do modelu $\mathrm{M}_{1}$ ) charakteryzował się też najsłabszym dopasowaniem do danych empirycznych. Błąd prognozy, wyznaczonej na podstawie klasycznego modelu przyczynowo-opisowego $M_{3}$, o najwyższym dopasowaniu do rzeczywistych danych, jest tylko o 1,65 pp. niższy od błędów najmniej trafnych prognoz otrzymanych na podstawie modeli $\mathrm{M}_{1}$ i $\mathrm{M}_{2}$.

W ostatnim etapie badań przeprowadzono testowanie obejmowania modeli względem prognoz z wykorzystaniem prognoz kombinowanych. Testowanie przeprowadzono dla par modeli (wszystkich dwuelementowych kombinacji ze zbioru $\left\{M_{1}, M_{2}, \ldots, M_{6}\right\}$ ) oraz dla wszystkich sześciu modeli jednocześnie. Ponieważ szereg prognoz ex-post jest dość krótki, w równaniach regresji (2) i (7), poza błędami prognoz dla $t=49,50, \ldots, 60$, wykorzystano też reszty modeli dla $t=1,2, \ldots, 48$ (umownie, dla uproszczenia zapisu, dalej będzie mowa o błędach prognoz). W tabelach 3 i 4 zestawiono otrzymane wartości statystyk (odpowiednio $t$ i $F$ ) przy poziomie istotności 0,05 oraz empiryczne poziomy istotności testów p-value. 
Tabela 3. Wartości statystyki $t$

\begin{tabular}{|c|c|c|c|}
\hline Model & Model rywalizujący & $t$ & $p$-value \\
\hline \multirow{5}{*}{$M_{1}$} & $M_{2}$ & 0,04 & 0,925 \\
\hline & $\mathrm{M}_{3}$ & 1,98 & 0,160 \\
\hline & $\mathrm{M}_{4}$ & 1,67 & 0,172 \\
\hline & $\mathrm{M}_{5}$ & 3,86 & 0,023 \\
\hline & $M_{6}$ & 6,69 & 0,009 \\
\hline \multirow{5}{*}{$\mathrm{M}_{2}$} & $M_{1}$ & 1,24 & 0,184 \\
\hline & $\mathrm{M}_{3}$ & 2,48 & 0,024 \\
\hline & $\mathrm{M}_{4}$ & 1,85 & 0,193 \\
\hline & $\mathrm{M}_{5}$ & 4,32 & 0,012 \\
\hline & $M_{6}$ & 7,80 & 0,010 \\
\hline \multirow{5}{*}{$M_{3}$} & $M_{1}$ & $-0,93$ & 0,777 \\
\hline & $\mathrm{M}_{2}$ & $-0,51$ & 0,910 \\
\hline & $\mathrm{M}_{4}$ & 0,84 & 0,898 \\
\hline & $\mathrm{M}_{5}$ & 3,78 & 0,023 \\
\hline & $\mathrm{M}_{6}$ & 6,72 & 0,015 \\
\hline \multirow{5}{*}{$\mathrm{M}_{4}$} & $M_{1}$ & 2,30 & 0,023 \\
\hline & $\mathrm{M}_{2}$ & 1,08 & 0,770 \\
\hline & $\mathrm{M}_{3}$ & 3,86 & 0,013 \\
\hline & $\mathrm{M}_{5}$ & 5,12 & 0,011 \\
\hline & $M_{6}$ & 6,80 & 0,009 \\
\hline \multirow{5}{*}{ M5 } & $M_{1}$ & 0,59 & 0,623 \\
\hline & $\mathrm{M}_{2}$ & 0,47 & 0,812 \\
\hline & $M_{3}$ & 1,24 & 0,217 \\
\hline & $\mathrm{M}_{4}$ & 0,98 & 0,509 \\
\hline & $M_{6}$ & 4,59 & 0,013 \\
\hline \multirow{5}{*}{$M_{6}$} & $M_{1}$ & 0,42 & 0,658 \\
\hline & $\mathrm{M}_{2}$ & 0,97 & 0,437 \\
\hline & $M_{3}$ & 1,43 & 0,095 \\
\hline & $M_{4}$ & 1,28 & 0,101 \\
\hline & $\mathrm{M}_{5}$ & 7,42 & 0,008 \\
\hline
\end{tabular}

Analizując informacje zestawione w tab. 3, można zauważyć, że w przypadku modelu $\mathrm{M}_{1}$ statystycznie nieistotne są tylko parametry w równaniach regresji (2), w których zmiennymi objaśniającymi są różnice pomiędzy błędami prognoz wyznaczonych na podstawie modelu $M_{1}$ oraz modeli $M_{2}, M_{3}$ i $M_{4}$. Oznacza to, że model $M_{1}$ obejmuje wymienione trzy modele rywalizujące (każdy z osobna), natomiast nie obejmuje modeli $\mathrm{M}_{5}$ i $\mathrm{M}_{6}$.

Dla modelu $\mathrm{M}_{2}$ statystycznie nieistotne są parametry w równaniach regresji (2), w których zmienną objaśnianą są błędy prognoz wyznaczonych na podstawie modelu $M_{2}$, a zmiennymi objaśniającymi są różnice pomiędzy błędami prognoz wyznaczonych na podstawie modelu $M_{2}$ oraz modeli $M_{1}$ i $M_{4}$. Oznacza to, że model $M_{2}$ obejmuje modele rywalizujące $M_{1}$ i $M_{4}$, natomiast nie obejmuje modeli $\mathrm{M}_{3}, \mathrm{M}_{5}$ i $\mathrm{M}_{6}$.

Analizując dalej w analogiczny sposób informacje zestawione w tab. 3, można zauważyć, że:

- model $M_{3}$ obejmuje modele $M_{1}, M_{2}$ i $M_{4}$, a nie obejmuje modeli $M_{5}$ i $M_{6}$,

- model $\mathrm{M}_{4}$ obejmuje tylko model $\mathrm{M}_{2}$,

- model $M_{5}$ obejmuje wszystkie modele, poza $M_{6}$,

- model $M_{6}$ obejmuje wszystkie modele, poza $M_{5}$.

Można zauważyć, że obejmowanie względem prognoz nie jest relacją zwrotną - choć modele $\mathrm{M}_{1}$ i $\mathrm{M}_{2}$ wzajemnie się obejmują, jednak w przypadku modeli $\mathrm{M}_{2}$ i $\mathrm{M}_{3}$ zachodzi tylko jednostronne obejmowanie modelu $M_{2}$ przez $M_{3}$. Obejmowanie względem prognoz jest za to 
w rozważanym przykładzie empirycznym relacją przechodnią, np. model $M_{1}$ obejmuje $M_{4}$, który $z$ kolei obejmuje $\mathrm{M}_{2}$, ponadto model $\mathrm{M}_{1}$ obejmuje $\mathrm{M}_{2}$.

Wyniki testowania obejmowania modeli wskazują, że do zbioru najlepszych modeli można zaliczyć $M_{5}$ i $M_{6}$ - nie obejmują się one wzajemnie i żaden z nich nie jest obejmowany przez pozostałe modele rywalizujące. Kolejnym modelem, który można włączyć do modeli preferowanych, jest $M_{3}$, gdyż obejmuje on wszystkie modele, poza $M_{5}$ i $M_{6}$. Pozostałe modele trudno jest zaliczyć do najlepszych, ponieważ są one obejmowane przez wyróżnione modele $M_{3}, M_{5}$ i $M_{6}$, ponadto modele te $w$ większości wzajemnie się obejmują.

W tabeli 4 przedstawiono wyniki testowania obejmowania modeli względem prognoz na podstawie równania regresji (7). Zmienną zależną w każdym szacowanym równaniu jest wektor błędów prognoz wyznaczonych na podstawie jednego modelu $M_{i}(i=1,2, \ldots, 6)$, natomiast zmiennymi niezależnymi są różnice pomiędzy błędami prognoz wyznaczonych na podstawie modelu $M_{i}$ oraz pozostałych pięciu modeli rywalizujących ze zbioru $\left\{M_{1}, M_{2}, \ldots, M_{6}\right\}$.

Tabela 4. Wartości statystyki $F$

\begin{tabular}{|l|c|c|c|}
\hline \multicolumn{1}{|c|}{ Model } & Modele rywalizujące & $F$ & p-value \\
\hline$M_{1}$ & $M_{2}, M_{3}, M_{4}, M_{5}, M_{6}$ & 22,02 & 0,00002 \\
\hline$M_{2}$ & $M_{1}, M_{3}, M_{4}, M_{5}, M_{6}$ & 31,91 & 0,00001 \\
\hline$M_{3}$ & $M_{1}, M_{2}, M_{4}, M_{5}, M_{6}$ & 11,72 & 0,00002 \\
\hline$M_{4}$ & $M_{1}, M_{2}, M_{3}, M_{5}, M_{6}$ & 17,84 & 0,00002 \\
\hline$M_{5}$ & $M_{1}, M_{2}, M_{3}, M_{4}, M_{6}$ & 45,43 & 0,00001 \\
\hline$M_{6}$ & $M_{1}, M_{2}, M_{3}, M_{4}, M_{5}$ & 34,73 & 0,00001 \\
\hline
\end{tabular}

Po oszacowaniu równań regresji (7) dla kolejnych modeli okazało się, że w każdym z równań co najmniej jeden parametr różni się istotnie od zera. $Z$ analizy informacji zawartych $w$ tab. 4 wynika, iż na podstawie wartości statystyki $F$ należy odrzucić hipotezę zerową o jednoczesnej nieistotności wszystkich parametrów (wag prognozy kombinowanej). Wynika stąd, że żaden z sześciu modeli nie obejmuje jednocześnie wszystkich pozostałych modeli rywalizujących.

\section{PODSUMOWANIE}

Dokonując wyboru najlepszego modelu na podstawie miar dobroci dopasowania oraz błędów prognoz, można uporządkować rywalizujące modele. W przedstawionym przykładzie empirycznym na podstawie oceny miar dobroci dopasowania preferowany jest model $M_{3}$, następnie kolejno $\mathrm{M}_{1}, \mathrm{M}_{4}$ i $\mathrm{M}_{2}$. Na podstawie oceny trafności prognoz ex-post preferowany jest model $M_{6}$, potem $M_{5}$, natomiast $w$ grupie pozostałych modeli (dla których badano też dopasowanie za pomocą miar dobroci) najlepszy jest model $M_{3}$, potem $M_{4}$, a na końcu modele ex aequo $\mathrm{M}_{1}$ i $\mathrm{M}_{2}$. Uwzględniając zatem jednocześnie oba przypadki - miary dobroci dopasowania oraz błędy prognoz - preferowany jest model $M_{3}$, natomiast kolejność pozostałych jest już nieco inna.

Testowanie obejmowania modeli względem prognoz pozwala na bezpośrednie porównanie rywalizujących modeli, lecz, jak widać w przedstawionym przykładzie empirycznym, trudno jest dokonać ich dokładnego uporządkowania, gdyż nie są tutaj ważne same wartości 
statystyk $t$ i $F$, a jedynie ich wartości, w porównaniu z krytycznymi wartościami testu. Można zatem ustalić jedynie zbiór modeli preferowanych, które mają przewagę nad pozostałymi. Podobnie jak przy wyborze modelu na podstawie miar dobroci dopasowania oraz błędów prognoz, do zbioru modeli najlepszych należą również modele $\mathrm{M}_{5}$ i $\mathrm{M}_{6}$ oraz $\mathrm{M}_{3}$. Pozostałe modele są obejmowane przez wyróżnione trzy modele.

Z powyższych rozważań wynika, że testowanie obejmowania modeli względem prognoz jest użyteczną metodą wyboru kilku najlepszych modeli (modeli preferowanych) ze zbioru dostępnych modeli rywalizujących. Może stanowić uzupełnienie bądź alternatywne rozwiązanie dla arbitralnego wyboru na podstawie samych miar dobroci dopasowania do danych empirycznych czy błędów prognoz. Należy jednak zwrócić uwagę na to, iż korzystniejsze jest testowanie obejmowania dla par modeli, a nie wszystkich modeli jednocześnie.

Testowanie obejmowania modeli względem prognoz daje możliwość bezpośredniego porównania modeli rywalizujących również w przypadku, gdy nie są znane realizacje prognozowanej zmiennej. Wówczas w szacowanych równaniach regresji (2) i (7) w miejsce błędów prognoz wystarczy podstawić same wartości reszt dostępnych modeli.

Testowanie obejmowania modeli względem prognoz nie wymaga budowy prognozy kombinowanej - szacuje się tylko równanie regresji, którego parametry są jej wagami. Wyznaczenie prognozy kombinowanej wymagałoby jeszcze wykonania prostego przekształcenia zsumowania wartości teoretycznych oszacowanej funkcji regresji oraz rzeczywistych wartości modelowanej zmiennej. Testowanie obejmowania modeli względem prognoz może być wskazówką przy wyborze kombinacji prognoz indywidualnych uwzględnionych w prognozie ważonej, gdyż sama metoda jej budowy w ogóle nie wymaga badania istotności parametrów. Pozwala na redukcję zbioru dostępnych modeli i wyznaczonych na ich podstawie prognoz, tym samym wskazując, które prognozy indywidualne o nieistotnych statystycznie wagach można wykluczyć z kombinacji.

\section{PIŚMIENNICTWO}

Bates J., Granger C. 1969. The combination of forecasts. Operat. Res. Quart. 20, 451-468.

Charemza W., Deadman D. 1997. Nowa ekonometria. Warszawa, PWE.

Chong Y., Hendry D. 1986. Econometric evaluation of linear macro-economic models. Rev. Econ. Stud. 53, 671-690.

Clements M., Hendry D. 1993. On the limitations of comparing mean square forecast errors. J. Forecast. 12, 617-637.

Granger C., Newbold P. 1973. Some comments on the evaluation of economic forecasts. App. Econ. 5, $35-47$.

Harvey D., Newbold P. 2000. Tests for multiple forecast encompassing. J. App. Econometr.15, 471-482.

Harvey D., Newbold P. 2002. Forecast combination and encompassing, in: A companion to economic forecasting. Red. M. Clements, D. Hendry. Oxford, Blackwell.

Mizon G., Richard J. 1986. The encompassing principle and its application to testing non-nested hypotheses. Econometrica 54, 657-678.

Pawłowski Z. 1968. Teoria prognozy ekonometrycznej w gospodarce socjalistycznej. Warszawa, PWN.

Perzyńska J. 2010. Budowa prognoz kombinowanych z wykorzystaniem sztucznych sieci neuronowych. Pr. UE Wroc. 103 (Prognozowanie w zarządzaniu firmą),133-145.

Welfe W., Welfe A. 2004. Ekonometria stosowana. Warszawa, PWE. 
Wprowadzenie do ekonometrii w przykładach i zadaniach. 2004. Red. K. Kukuła. Warszawa, Wydaw. Nauk. PWN.

Zastosowanie hierarchicznych modeli szeregów czasowych w prognozowaniu zmiennych ekonomicznych z wahaniami sezonowymi. 2003. Red. J. Zawadzki. Szczecin, AR.

Streszczenie. W artykule autor rozważa sytuację, w której dostępne są różne modele ekonometryczne tej samej zmiennej. Podstawowym problemem jest wówczas wybranie najlepszego modelu. Najczęściej w tym celu stosuje się miary dopasowania modelu do danych empirycznych. Alternatywnym podejściem może być testowanie obejmowania modeli. W artykule przestawione są rozważania teoretyczne dotyczące testowania obejmowania modeli względem prognoz. Wykorzystuje się w nim metodologię budowy prognoz kombinowanych będących średnimi ważonymi prognoz indywidualnych wyznaczonych na podstawie rywalizujących modeli. Ilustracją rozważań teoretycznych jest przykład empiryczny, w którym modelowaniu i prognozowaniu poddano koszty produkcji energii cieplnej i elektrycznej w elektrowni B. 
